\title{
Impacts of male-only fishing and sperm limitation in manipulated populations of an unfished crab, Hapalogaster dentata
}

\author{
Taku Sato*, Seiji Goshima \\ Laboratory of Marine Biodiversity, Graduate School of Fisheries Sciences, Hokkaido University, Hakodate, \\ Hokkaido 041-8611, Japan
}

\begin{abstract}
We examined how changes in population structure resulting from fishing selectively for males, including a decrease in male size and a skewed sex ratio toward females, might influence the reproductive success of females in fished populations. We used Hapalogaster dentata as a model species for commercially important lithodid crabs. First, to verify the validity of using $H$. dentata as a model species, we examined the effects of male size and mating frequency on both male and female reproductive potentials of $H$. dentata. Male and female reproductive potential was very similar to some commercially important lithodid crabs. Male size and mating frequency affected the reproductive success of females, due to sperm limitation. Females had a limited period of sexual receptivity. These reproductive characteristics would be valid for using $H$. dentata as a model species. Second, to investigate the reproductive success of females in populations, we placed 16 artificial populations of $H$. dentata in artificial cobble plots similar to their natural habitat. The male size and sex ratio of these populations were manipulated. A sharp decrease in female reproductive success in response to their mating timing was observed in the populations comprising small males with a sex ratio skewed toward females. Additionally, the mean reproductive success of females in manipulated populations (i.e. SB population) decreased gradually as the reproductive season progressed. Our results indicate that a decrease in male size and a sex ratio skewed by male-only fishing would sharply decrease the reproductive success of females by sperm limitation. Commercially important lithodid crabs can be similarly impacted unless the legal size limit for males is adequate.
\end{abstract}

KEY WORDS: Population structure $\cdot$ Male-only fishing $\cdot$ Sperm limitation $\cdot$ Male size $\cdot$ Male mating frequency $\cdot$ Sperm recovery rate $\cdot$ Hapalogaster dentata

\section{INTRODUCTION}

Sperm production is costly and slow (Dewsbury 1982), and so males do not always have sufficient sperm to fertilize all eggs spawned by females (Nakatsuru \& Kramer 1982, Gage \& Cook 1994, Pitnick \& Markow 1994, Preston et al. 2001, Sato et al. 2005b, 2006). Insufficient sperm supply from males limits reproductive success of females (e.g. Royer \& McNeil 1993, Svensson et al. 1998, MacDiarmid \& Butler 1999, Rondeau \& Sainte-Marie 2001, Sato et al. 2005b, 2006). An insufficient sperm supply received by females may be related to population structure because male size and mating frequency influences sperm supply. For example, larger males often hold more sperm than smaller males (Pitnick 1996, Jivoff, 1997, Kendall et al. 2001, Sato et al. 2005b, 2006), and therefore sperm supply is less in populations with only small males. When the sex ratio in a population is skewed toward females, male mating frequency increases. Because males deplete their sperm reserves through successive matings (Dewsbury 1982, Rutowski et al. 1987, Birkhead 1991, Pitnick \& Markow 1994, Bissoondath \& Wiklund 1996, Sato et al. 2005b), female fertilization success may be reduced in a population with a femalebiased sex ratio. 
Fishing may change population structure. For example, only large males are selectively harvested in many large decapod crustacean fisheries (e.g. Ennis et al. 1990, Smith \& Jamieson 1991). Fishing only large males decreases the mean male size and skews the sex ratio toward females (Paul \& Adams 1984, Ennis et al. 1988, Cole et al. 1990, Abbe \& Stagg 1996, Sato et al. 2005b). In fished populations, small mature males may replace large males in reproduction (Ennis et al. 1988, 1990, Sainte-Marie 1993) and experience more matings than in non-fished populations (Powell et al. 1974, Ennis et al. 1988, 1990, Sainte-Marie 1993). Therefore, sperm limitation may occur in some fished crabs.

Reproductive success of fished crab populations may also be affected by mate encounter frequency of females. A decrease in male crab density by male-only fishing reduces the frequency of female encounters with males and causes difficulty for females to find mates, as seen in some large decapod species (Gray \& Powell 1964, Powell et al. 1974, Ennis 1980, Smith \& Jamieson 1991). In fished crab populations comprised of fewer males, males would deplete their sperm reserves because of the large number of successive matings. In consequence, the number of males available to mate decreases progressively in fished populations as the reproductive season progresses. This would delay mating of female crabs. Negative effects of delayed mating on spawning, fertilization, and development of eggs have been reported (McMullen 1969, Paul \& Adams 1984, Sainte-Marie \& Lovrich 1994, Sato et al. 2005a). In fished crab populations consisting of fewer males, delayed female mating may also decrease their reproductive success.

However, little is known about the influence of maleonly fishing on the reproductive success of fished crab populations (Hankin et al. 1997, Sainte-Marie et al. 2002, Hines et al. 2003), degree and pattern of decrease in reproductive success of females due to sperm limitation, and the extent of delayed mating. Because most large decapod crabs live in the deep sea, field investigations are difficult. As all large decapod crab populations are affected by commercial fishery, estimation of the actual influences of commercial maleonly fishing on the reproductive success of crab stocks is almost impossible. However, resolution of these questions is important for adequate management of the crab resources.

The stone crab Hapalogaster dentata is an ideal model anomuran species to investigate the influence of changes in population structure due to male-only fishing on the reproductive success of populations. $H$. dentata is closely related to commercially important lithodid crabs, such as king crab (Cunningham et al. 1992). Although it differs from commercially important crabs in some ways, such as smaller body size, lower fecundity, and a lack of seasonal or size-dependent migration, its reproductive behavior strongly resembles that of commercially important lithodid crabs (Goshima et al. 1995). H. dantata inhabit intertidal and subtidal cobble rocky shores throughout their life, so field investigation is relatively easy. They hide and cling under cobbles, and individuals that move away from cobbles are rarely seen, suggesting that this species has low mobility (K. Yoshino unpubl. data), which enables the population structure to be manipulated without difficulty. They are not fished. Therefore, their population structure can be manipulated without fishery interference to compare the reproductive success of populations of different demographic structures. For example, the reproductive success of populations with many large males may be compared with that of populations having only small males.

In this study, we used Hapalogaster dentata as a model to investigate the influence of changes in population structure, caused by male-only removals, on reproductive success. First, to verify the validity of using $H$. dentata as a model species for commercially important lithodid crabs, such as king crab, we examined: (1) relationships between male size and their reproductive potential (the relationship between male size and number of sperm, the amount of ejaculated sperm, the ability of males to mate repeatedly, and the relationship between male size and sperm recovery rate), and (2) the reproductive potential of females (the relationship between female size and number of eggs spawned, and the effect of delayed mating on female reproductive success). Second, we formed 16 artificial stone crab populations whose population structure we manipulated, and then we investigated the relationship between reproductive success of females and population structure.

\section{MATERIALS AND METHODS}

Hapalogaster dentata was collected on an intertidal rocky shore in Kattoshi on the southwest side of Hakodate Bay, southern Hokkaido, Japan $\left(41^{\circ} 44^{\prime} \mathrm{N}\right.$, $140^{\circ} 36^{\prime} \mathrm{E}$ ) before each reproductive season in 2000 to 2002. Goshima et al. $(1995,2000)$ reported its life history and ecology. Its reproductive season is from early October to late November, females spawn once a year, and eggs are incubated for about $110 \mathrm{~d}$. Female size at sexual maturity is $8 \mathrm{~mm}$ carapace length (CL); male size at gonadal maturity estimated by histological examination of the testis and vasa deferentia is $5.3 \mathrm{~mm}$ CL. During the reproductive season, a male guards a ripe unmolted female just before female molting by grasping her or covering her with his body. Females cannot mate before molting. The guarded female molts 
and immediately spawns after mating. The period between mating and spawning is approximately $20 \mathrm{~min}$ (T. Sato unpubl. data) and females have no spermatheca to store sperm, so that most females would mate with 1 male in a reproductive season. Males can have many matings in a reproductive season, hold many sperm-packed spermatophores in their vasa deferentia and attach spermatophores to the abdomen of females near the gonopores during mating. Mated females fertilize their eggs externally within the brood chamber formed by the abdomen. In laboratory observations, both females and males have multiple reproductive seasons during a lifetime.

In the study area, wide cobble zones extend to about $200 \mathrm{~m}$ offshore. Crabs were sampled by turning over or lifting cobbles during low tide. All captured crabs were sexed by the shape of the abdomen, their CL was measured to the nearest $0.1 \mathrm{~mm}$ using vernier calipers, and they were transported to Usujiri Marine Station, Aquatic Research Station, Field Science Center for

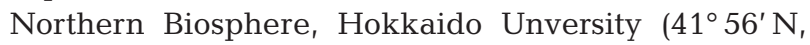
$\left.140^{\circ} 57^{\prime} \mathrm{E}\right)$ where all laboratory experiments were done. Only intact individuals were used in experiments. Crabs were fed an artificial diet of fish meals. During the experiments, a natural light-dark regime was used, and the seawater temperature was 10.0 to $19.9^{\circ} \mathrm{C}$.

Relationships between male size and male reproductive potential. First, to count the number of sperm, sperm was extracted from spermatophores using $20 \%$ $\mathrm{NaOH}$ solution (Sato et al. 2004). We examined the adequate soaking time for all packed sperm to be released from spermatophores and the time that sperm resists dissolution by $20 \% \mathrm{NaOH}$ solution. A total of 800 spermatophores were removed from vasa deferentia of each mature male $(n=5)$ under a stereomicroscope; every 200 spermatophores were put into each of 4, $1 \mathrm{ml}$ microtubes containing $0.2 \mathrm{ml} 20 \% \mathrm{NaOH}$ solution. At 15, 30, 60 or 90 min after soaking in $20 \%$ $\mathrm{NaOH}$ solution, the contents of 1 microtube were mixed by using a vortex-type mixer for $30 \mathrm{~s}$. Each mixed solution was then placed immediately into a Thoma hemacytometer. Sperm in $0.1 \mu \mathrm{l}$ of the solution were then counted under an optical microscope and then total number of extracted sperm in each microtube was calculated. The counts were repeated 4 times for each tube, and the average of the 4 counts was used as the number of sperm in each tube. The mixed solutions were examined immediately after the sperm counts to confirm the condition of spermatophores, and the hemacytometers were retained. At $120 \mathrm{~min}$ after mixing, we examined the condition of sperm in the hemacytometer again, and re-counted the number of sperm in the grid of the hemacytometer to confirm if sperm were dissolved. Data of the number of extracted sperm were tested for homogeneity of variances by using the Levene test and were analyzed with 1-way ANOVA. A Tukey-Kramer multiple-comparisons test was used to identify significant differences between soaking time treatments.

Second, we examined the relationship between male size and the number of sperm retained by males. Vasa deferentia were removed from intact and hard-shell male crabs (CL 6.4-18.0 mm, $\mathrm{n}=89$ ) under a stereomicroscope, and were put into $15 \mathrm{ml}$ tubes with $10 \mathrm{ml}$ or $2 \mathrm{ml} 20 \% \mathrm{NaOH}$ solution depending on the size of the vasa deferentia. The total number of sperm was estimated by using the same method to find the adequate soaking time in $20 \% \mathrm{NaOH}$ solution. The relationship between the number of sperm in the vasa deferentia and male size was found by linear regression.

Third, we examined the relationship between the number of ejaculated sperm and male mating frequency. Nineteen males (CL 13.0-14.0 mm) and 76 unmolted females (pre-molting CL 9.0-10.0 mm) were used. Each male was placed in an aquarium $(19.5 \times$ $12 \times 7 \mathrm{~cm}$ ) containing about $1.5 \mathrm{l}$ of filtered seawater. Unmolted female crabs were placed in a tank $(244 \times$ $89 \times 18 \mathrm{~cm}$ ) containing some round stones with flowing filtered seawater. We checked the female tank every day for molts. If a female had molted, we transferred her to an aquarium containing a male for mating, and we observed them until they mated. Just after mating, the mated female was separated from the male and was removed carefully from the aquarium. The attached spermatophores were removed from her abdomen by cutting out parts of the female exoskeleton where the spermatophores were attached. These parts of the female exoskeleton were put into a $15 \mathrm{ml}$ tube filled with 5 or $2 \mathrm{ml} 20 \% \mathrm{NaOH}$ solution depending on the amount of ejaculated sperm. The total number of ejaculated sperm was counted and estimated with the same method used to find the adequate soaking time in $20 \% \mathrm{NaOH}$ solution. Each male was mated with 1 female per day over a period of $3 \mathrm{~d}$. The effect of male mating frequency on the amount of ejaculated sperm was analyzed by repeated measures ANOVA after testing with Mauchly's sphericity test.

Fourth, we examined the relationship between male size and male ability to mate successively. We used 63 males that had not mated in the reproductive season and divided them into 3 size classes: small male: CL 6.0-7.0 mm, $\mathrm{n}=23$; medium male: CL 9.0-10.0 mm, $\mathrm{n}=24$; large male: CL 13.0-14.0 mm, n = 16; 250 unmolted females (pre-molting CL 9.0-10.0 mm) were also used. The conditions of aquaria containing 1 male and tanks containing unmolted females were the same as those used to find the relationship between the amount of ejaculated sperm and male mating frequency. If the female had molted in the tank, she was 
transferred to an aquarium containing a male for mating. We checked every day to see if the molted female had spawned. After spawning, the female was moved from the aquarium to another aquarium (19.5 $\times$ $12 \times 7 \mathrm{~cm}$ ) that contained about $1.5 \mathrm{l}$ of filtered seawater, and another molted female was transferred to the same aquarium containing the mated male as his next mate. Every male mated with 1 molted female per day and mated with 5 females in succession or until the male was incapable of inducing females to spawn within $2 \mathrm{~d}$ of their transfer. When a male failed to induce a female to spawn, we judged that the male was incapable of mating with any female, and classified him as a 'depleted male'. About $3 \mathrm{~d}$ after spawning, when eggs have normally divided into 32 to 64 cells (T. Sato et al. unpubl. data), some eggs were collected randomly from 3 parts of the clutch by using a pair of tweezers, and the cell division of a total of 150 eggs was observed under a stereomicroscope. We used the percentage of dividing eggs as the fertilization rate in a female clutch. The effects of male size and male mating frequency on reproductive success of females, calculated as: spawning success (success = 1 or failure $=0) \times$ fertilization rate (0 to 100 ), were analyzed by using 2-way repeated measures ANOVA. Huynh-Feldt (H-F) corrected probability was used because the sphericity assumption was not met.

Fifth, we examined the relationship between male size and sperm recovery rate. We used 21 medium males (CL 9.1-10.0 mm), 21 large males (CL 13.0$13.9 \mathrm{~mm}$ ) and 189 unmolted females (pre-molting CL $9.0-12.0 \mathrm{~mm})$. The conditions of aquaria containing 1 male, tanks containing unmolted females and the treatment were the same used to find the relationship between the amount of ejaculated sperm and male mating frequency. If the female had molted in the tank, we transferred the molted female to an aquarium containing a male for mating. Every male mated with a molted female every day until he was depleted. At 0, 5, 10 or $20 \mathrm{~d}$ after the male depletion, the vasa deferentia were removed from the depleted male and were put into a $10 \mathrm{ml}$ tube filled with $2 \mathrm{ml}$ of $20 \% \mathrm{NaOH}$ solution. The total number of sperm in the vasa deferentia was counted and was estimated with the same method used to find the adequate soaking time in $20 \% \mathrm{NaOH}$ solution. The relationship between the number of days after depletion of the male and the number of sperm stored in the vasa deferentia of each male size class was analyzed by using 1-way ANOVA after testing for homogeneity of variances by the Levene test. The Tukey-Kramer multiple-comparisons test was used to identify significant differences between treatments.

Vasa deferentia were removed from 10 medium unmated males (CL 9.2-9.9 mm) and 9 large unmated males (CL 13.2-14.0 mm) before the reproductive sea- son in early October. We counted the number of sperm retained by unmated males by using the same method as in the fifth experiment, and compared the number of sperm retained by the unmated males with that of mated males allowed to recover for $20 \mathrm{~d}$ in each size class to estimate the degree of recovery rate of exhausted sperm. A 1-way ANOVA was used to identify significant differences in both male sizes after testing with a Levene test.

Female reproductive potential. First, we examined the relationship between female size and number of eggs spawned. Unmolted female crabs (pre-molting CL 7.8-13.8 mm, $\mathrm{n}=195)$ were placed in a tank $(244 \times$ $89 \times 18 \mathrm{~cm}$ ) containing some round stones with flowing filtered seawater. We checked every day to see if the females had molted. If females had molted, they were transferred to a separate aquarium $(19.5 \times 12 \times 7 \mathrm{~cm})$ that contained about $1.5 \mathrm{l}$ of filtered seawater with 1 female per aquarium, and added a large male (CL > $13.0 \mathrm{~mm}$ ) to each aquarium to induce the female to mate and spawn. At $2 \mathrm{~d}$ after spawning, all eggs were removed from the female pleopods by using a pair of tweezers and were counted, and the CL of the spawned females was measured. The relationship between female size (post-molting CL, mm) and number of eggs spawned was found by linear regression.

Second, we investigated the effects of delayed mating on the reproductive success (spawning success and fertilization rate) of females. Seventy females (premolting CL 9.0-10.0 mm) were placed in an aerated tank $(244 \times 89 \times 18 \mathrm{~cm})$ containing some round stones with flowing filtered seawater. If the females had molted in the tank, they were transferred to a separate aquarium $(19.5 \times 12 \times 7 \mathrm{~cm})$ that contained about $1.5 \mathrm{l}$ of filtered seawater with 1 female per aquarium. At 0 $(\mathrm{n}=15), 3(\mathrm{n}=16), 5(\mathrm{n}=23)$, or $7(\mathrm{n}=16) \mathrm{d}$ after the females molted, we added 1 male crab (10.3-12.3 mm $\mathrm{CL}$ ) to each aquarium to induce females to mate and spawn. We checked daily to see whether the females spawned after adding the male to estimate the sexually receptive duration after molting. When the molted female did not spawn within $2 \mathrm{~d}$ after the transfer, we judged that the female was not receptive. About $3 \mathrm{~d}$ after spawning, we observed the cell division and recorded the fertilization rate in her clutch by using the same method as to find the relationship between male size and male ability to mate successively, and then confirmed if the female mated. Simple linear regressions were used to find the relationship between the number of days after the female molt and the percentage of spawning success or fertilization rate.

Relationship between reproductive success of females and population structure. We used 16 Hapalogaster dentata populations having different male sizes and sex ratios. First, we made 16 plots from many cob- 
bles to simulate a habitat in the intertidal cobble rocky shore zone inhabited by $H$. dentata in Kattoshi before their reproductive season. Each plot was at least $6 \mathrm{~m}$ from other plots and consisted of many scattered cobbles formed into a square $5 \times 5 \mathrm{~m}$ on a shore of flat bedrock, and all cobbles around and between the plots were removed during low tide. All individuals of $H$. dentata already within the plots were removed, and were transported to another cobble zone far away from the plots.

Second, we collected 1600 mature crabs from outside the plots, transported them to the laboratory, and divided them into 5 groups based on sex and body size (small male: CL 6-10 mm, $\mathrm{n}=268$; large male: CL > $13 \mathrm{~mm}, \mathrm{n}=268$; small female: CL 8-9 mm, $\mathrm{n}=400$; medium female: CL 9-11 mm, $\mathrm{n}=400$; large female: $\mathrm{CL}>11 \mathrm{~mm}, \mathrm{n}=264$ ). Sixteen artificial populations were formed from the 5 groups with 100 individuals in each population. All individuals had a colored tape glued to their carapace to discriminate their sex and size class, the color differed depending on their group. The female:male sex ratio (SR) of the artificial populations was 1:1 or biased as 5:1. The female size distributions were equal among all artificial populations (small:medium:large female ratio $=3: 3: 2$ ). We formed 4 types of artificial populations consisting of the following sizes and ratios: (1) 50 small males (CL 6-10 mm) and 50 females (19 small, 19 medium, and 12 large females), $1: 1 \mathrm{SR}$ (= SE population $[n=4]$ because of the small male size distribution and equal SR); (2) 50 large males (CL > $13 \mathrm{~mm}$ ) and 50 females (19 small, 19 medium, and 12 large females), 1:1 SR (= LE population [ $\mathrm{n}=4$ ] because of the large male size distribution and equal SR); (3) 17 small males (CL 6-10 mm) and 83 females (31 small, 31 medium, and 21 large females), 5:1 SR, (= SB population [ $\mathrm{n}=4$ ] because of the small male size distribution and biased SR); (4) 17 large males (CL > $13 \mathrm{~mm}$ ) and 83 females (31 small, 31 medium, and 21 large females), 5:1 SR, (= LB population [ $n=4$ ] because of the large male size distribution and biased SR).

Third, in early October before the reproductive season, each artificial population was placed in each plot on the shore. During the reproductive season, we observed each plot 9 times at intervals of 3 to $8 \mathrm{~d}$ during low tide. When we found unmarked crabs, not in the artificial populations, that had strayed into the plot areas, we removed them from the plots. Eleven stray males were removed during reproductive season: 1 LB population had 6 stray males; 2 SE populations had 2 stray males; $1 \mathrm{SB}$ population had 1 stray male. In mid December, after the reproductive season, some females were collected from each artificial population (a total of 425 females were captured from the populations) and were transported to the laboratory. The female size (post-molting CL, mm) was measured, all eggs incubated by the females were removed by using a pair of tweezers, the egg development stage was noted, and only divided eggs were counted. To estimate the collected female fertilization rate, we used a regression formula between female size (post-molting CL) and number of spawned eggs and number of divided eggs incubated by the collected female. Nonfertilized eggs disintegrate and drop within at most $10 \mathrm{~d}$ in Hapalogaster dentata (T. Sato unpubl. data). Thus, the female fertilization rate was estimated by: (number of viable eggs incubated by the collected female/expected total number of eggs spawned by a female judged from the collected female body size) $\times 100$.

Fourth, to investigate the temporal change in fertilization rate of females in each population, we used the development stages of eggs incubated by the collected females. A difference in development stage of eggs results from different times of mating and spawning in the field. When we checked the development stage of incubated eggs after the reproductive season (middle of December), the development stage of each egg was the same within each clutch, but not between the collected females. In this study, collected females were divided into 2 groups based on the development stage of eggs: (1) if a female had eggs with eyespots, we concluded the female had mated and spawned in the early reproductive season, and classified the female in the early-mating group; (2) if a female had eggs without eyespots, the female was classified in the late-mating group.

For each population and time of female mating, the estimated fertilization rates of females were averaged, and then these mean fertilization rates were used in statistical analysis (each population structure and time of female mating had 4 replicates). The effects of population structure (male size and SR) and time of female mating on fertilization rates of females were estimated by using 3-way ANOVA after logtransformed data sets were tested for homogeneity of variances by using the Cochran test. The Bonferroni multiple-comparisons test was used to identify significant differences between treatments.

We also investigated the effects of female size and the time of female mating on the fertilization rate of females in SB populations having a female-biased SR. The collected females were classified into 2 groups based on female size (small females, post-molting CL 8-11 mm; large females, post-molting CL >11 $\mathrm{mm}$ ) to equalize the sample size approximately between each group. For each female size-class and time of female mating, the estimated fertilization rates of females were averaged, and then these mean fertilization rates were used in statistical analysis (each female size-class 
and female mating timing had 4 replicates). A significant difference was detected by 2-way ANOVA after homogeneity of variance was confirmed by the Levene test.

\section{RESULTS}

\section{Relationships between male size and male reproductive potential}

The number of extracted sperm was significantly different between the treatments (mean $\pm 1 \mathrm{SE}, 15 \mathrm{~min}$ : $1.04 \pm 0.16 \times 10^{4} ; 30 \mathrm{~min}: 1.68 \pm 0.20 \times 10^{4} ; 60 \mathrm{~min}:$ $3.04 \pm 0.10 \times 10^{4} ; 90 \mathrm{~min}: 3.04 \pm 0.10 \times 10^{4}$ (1-way ANOVA, $F_{3,16}=48.5, \mathrm{p}<0.001$, Levene test, $\mathrm{p}=0.67$ ). Tukey-Kramer multiple-comparisons showed significant differences between all combinations of the 4 treatments, except between 60 and $90 \mathrm{~min}$. Some unruptured spermatophores were seen only in the 15 and 30 min treatments. In the 30 min treatment, unruptured spermatophores were few, but sperm cells occurred in aggregates. At 120 min after mixing, sperm cell bodies were intact, but the spines of sperm had been dissolved. The number of sperm in the grid of the hemacytometer was equivalent to the first count of the number of sperm after mixing. Accordingly, all spermatophores were ruptured, and all sperm were released from spermatophores in $60 \mathrm{~min}$ by $20 \%$ $\mathrm{NaOH}$ solution. We found the optimal procedure for the stone crab was to soak spermatophores for $60 \mathrm{~min}$ in $20 \% \mathrm{NaOH}$ solution before mixing, and to count the sperm within 120 min after mixing.

The number of sperm in the vasa deferentia increased significantly with increasing male size (Fig. 1). The ejaculated size decreased significantly with in-

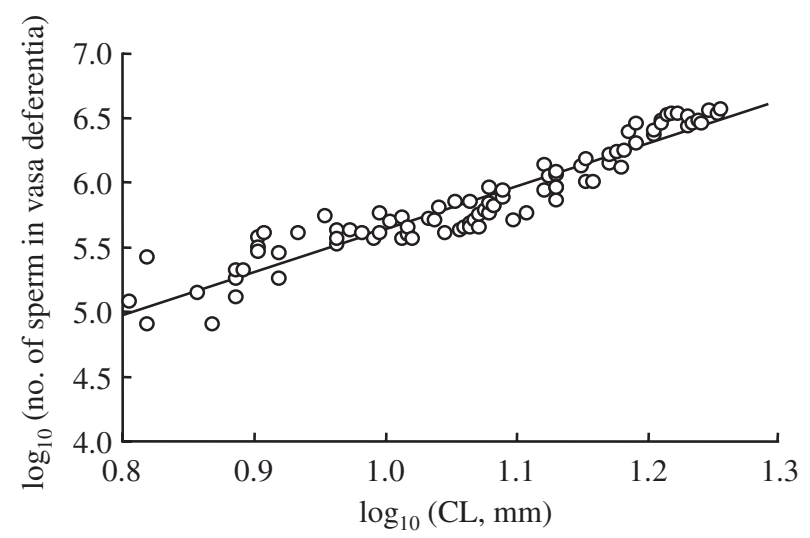

Fig. 1. Hapalogaster dentata. Relationship between male size and the number of sperm in the vasa deferentia retained by males. Regression fitted to log-transformed data are significant $\left(\log _{10}\right.$ Number of sperm in vasa deferentia $=3.28$ $\left.\log _{10} \mathrm{CL}+2.35, F_{1,87}=753.54, \mathrm{r}^{2}=0.90, \mathrm{n}=89, \mathrm{p}<0.001\right)$

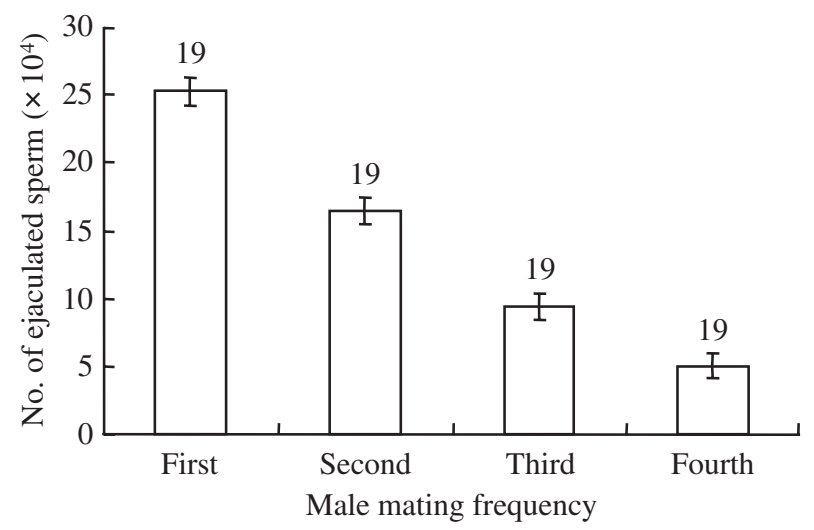

Fig. 2. Hapalogaster dentata. Relationship between male mating frequency and number of ejaculated sperm. Numbers above bars indicate sample size. Error bars are SE

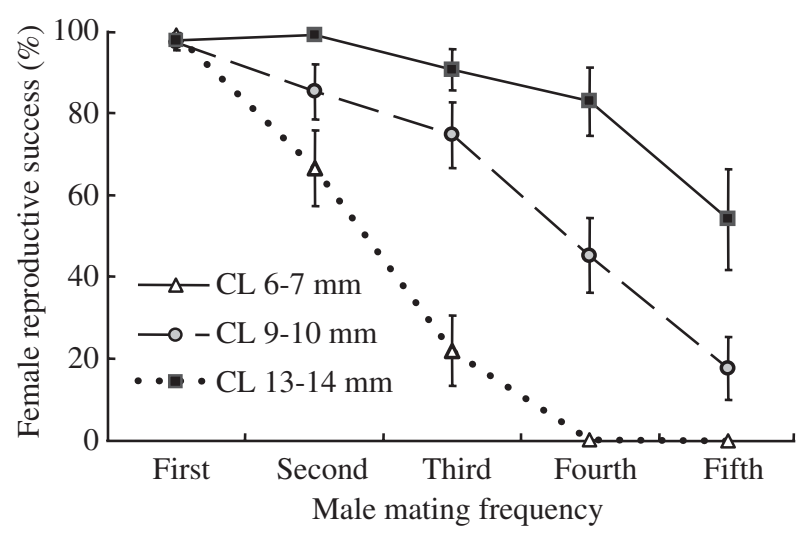

Fig. 3. Hapalogaster dentata. Relationship between mating frequency by males of various body sizes and the reproductive success of females (spawning success $\times$ fertilization rate). CL 6.0-7.0 mm, $\mathrm{n}=23$; $\mathrm{CL} 9.0-10.0 \mathrm{~mm}, \mathrm{n}=24$; $\mathrm{CL}$ 13.0-14.0 mm, $\mathrm{n}=16$. Error bars are $\mathrm{SE}$

creasing male mating frequency (repeated measures ANOVA, $F_{3,54}=93.26, \mathrm{p}<0.001$; Mauchly's sphericity test, df $=5, W=0.71, \mathrm{p}=0.35$, Fig. 2).

The degree of decline in female reproductive success with increasing male mating frequency was significantly different between the male size classes (2-way repeated measured ANOVA, male size $\times$ male mating frequency: $F_{7.143,214.279}=8.815, \mathrm{p}<0.001$; Mauchly's sphericity test, df $=9, W=0.68, \mathrm{p}=0.007$; Huynh-Feldt epsilon $=0.89$, Fig. 3). As male size decreased, the decline in female reproductive success with increasing male mating frequency was greater than for females mated with larger males. All small males failed to induce females to spawn in their 4 th and 5 th mating.

The number of sperm in the vasa deferentia of large males was significantly different with number of days 


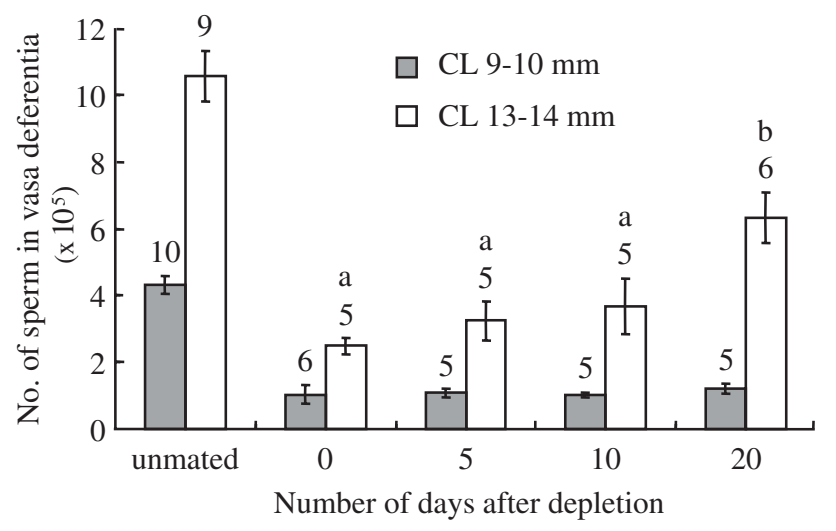

Fig. 4. Hapalogaster dentata. Recovery rate of number of sperm in the vasa deferentia retained by males differing in body size, and number of sperm in the vasa deferentia by unmated males. Different letters or number above the bar indicate significant differences or sample size. Error bars are SE

after male depletion (1-way ANOVA, $F_{3,17}=6.91, \mathrm{p}=$ 0.003; Levene test, $p=0.24$, Fig. 4). The Tukey-Kramer multiple-comparisons test showed significant differences between 0 and $20 \mathrm{~d}(\mathrm{p}=0.003), 5$ and $20 \mathrm{~d}(\mathrm{p}=$ $0.017)$, and 10 and $20 \mathrm{~d}(\mathrm{p}=0.045)$ after male depletion. The sperm in the vasa deferentia of large males increased over time after male depletion. However, the number of sperm in the vasa deferentia was significantly different between unmated large males and mated large males allowed $20 \mathrm{~d}$ to recover after depletion (1-way ANOVA, $F_{1,13}=14.72, \mathrm{p}=0.002$; Levene test, $p=0.46$, Fig. 4 ). Thus, the number of sperm in the vasa deferentia did not recover completely even $20 \mathrm{~d}$ after depletion. However, the number of sperm in vasa deferentia of medium males was not significantly different between the treatments (1-way ANOVA, $F_{3,17}=$ $0.22, p=0.88$; Levene test, $p=0.12$, Fig. 4 ). The vasa deferentia between unmated medium males and mated medium males allowed $20 \mathrm{~d}$ to recover after depletion were significantly different (1-way ANOVA, $F_{1,13}=62.34, \mathrm{p}<0.001$; Levene test, $\mathrm{p}=0.093$, Fig. 4) .

\section{Female reproductive potential}

Significant relationships exist between female size and number of spawned eggs (Fig. 5). As the number of days after molting increased, the percentage of females spawning fertilized eggs decreased significantly (Fig. 6), and the percentage of females that extruded non-fertilized eggs before adding a male to the female aquarium increased more $(0 \mathrm{~d}, 0 \% ; 3 \mathrm{~d}$, $25 \% ; 5 \mathrm{~d}, 65.2 \% ; 7 \mathrm{~d}, 75 \%)$. Although some females in the 5 and $7 \mathrm{~d}$ treatments did not extrude non-fertilized eggs until adding a male, they did not spawn eggs

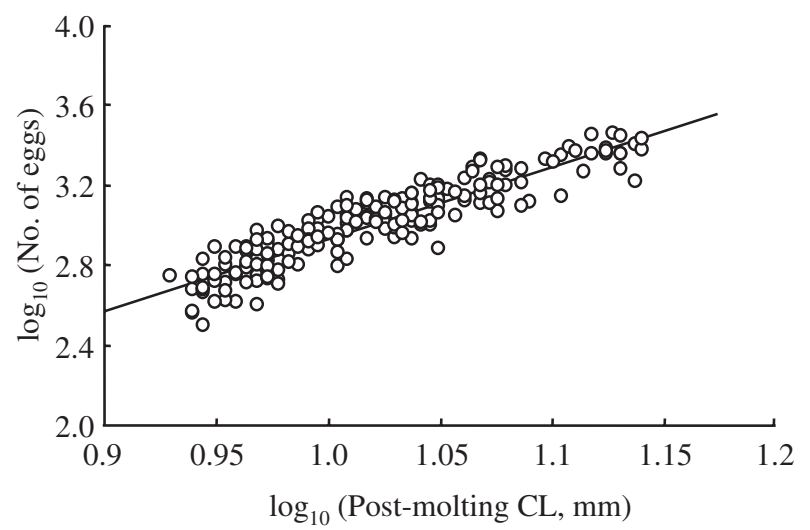

Fig. 5. Hapalogaster dentata. Relationship between female post-molting CL and number of eggs spawned. Regression fitted to log-transformed data is significant $\left(\log _{10}\right.$ Number of eggs $=3.63 \log _{10}$ Post-molting CL $-0.69, F_{1,193}=1034.57, \mathrm{r}^{2}=$ $0.84, \mathrm{n}=195, \mathrm{p}<0.001$ )

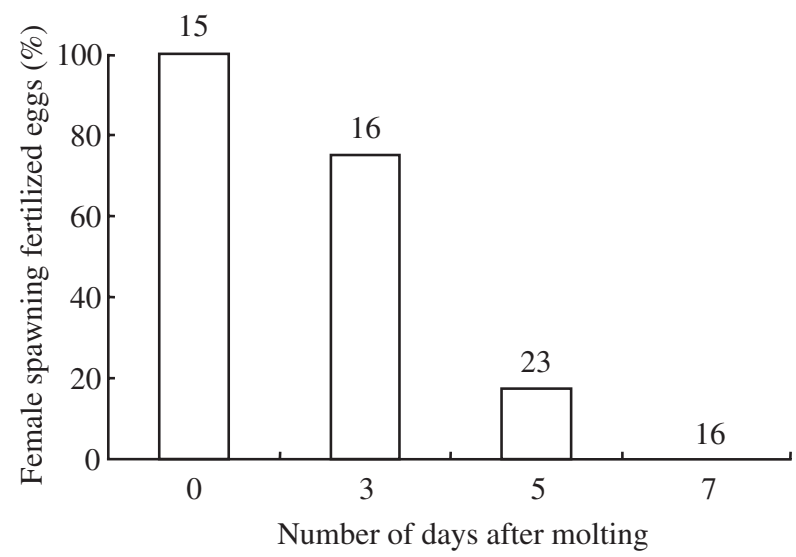

Fig. 6. Hapalogaster dentata. Relationship between spawning success and number of days from molting to mating of females. Regression is significant $\left(\log _{10}\right.$ Percent of female spawning fertilized eggs $=-15.31 \log _{10}$ Number of days after molting + 105.51, $\left.F_{1,2}=30.98, \mathrm{r}^{2}=0.94, \mathrm{n}=4, \mathrm{p}=0.031\right)$. Each number above the bar indicates sample size

even after a male was added $(5 \mathrm{~d}, 17.4 \%$ and $7 \mathrm{~d}, 25 \%$ of all females in each treatment). The fertilization rate of clutches and the number of days after molting had no significant relationship $\left(\log _{10}\right.$ Fertilization rate $=$ $-0.31 \times \log _{10}$ Number of days after molting +98.66 , $F_{1,29}=2.17, \mathrm{r}^{2}=0.07, \mathrm{n}=31, \mathrm{p}=0.15$ ).

\section{Relationship between reproductive success of females and population structure}

Females collected from each artificial population after the reproductive season were divided into 2 
Table 1. Hapalogaster dentata. Three-way ANOVA of the effects of male size, sex ratio, and timing of female mating on the estimated mean reproductive success of females. Cochran test: not significant

\begin{tabular}{|lcccr|}
\hline Source & df & MS & $F$ & \multicolumn{1}{c|}{ p } \\
\hline Male size (MS) & 1 & 0.131 & 64.455 & $<0.000$ \\
Sex ratio (SR) & 1 & 0.041 & 20.028 & $<0.000$ \\
Mating timing (MT) & 1 & 0.018 & 8.814 & 0.007 \\
MS $\times$ SR & 1 & 0.008 & 3.919 & 0.059 \\
MS $\times$ MT & 1 & 0.008 & 3.840 & 0.062 \\
SR $\times$ MT & 1 & 0.005 & 2.658 & 0.116 \\
MS $\times$ SR $\times$ MT & 1 & 0.003 & 1.626 & 0.214 \\
Error & 24 & 0.002 & & \\
\hline
\end{tabular}

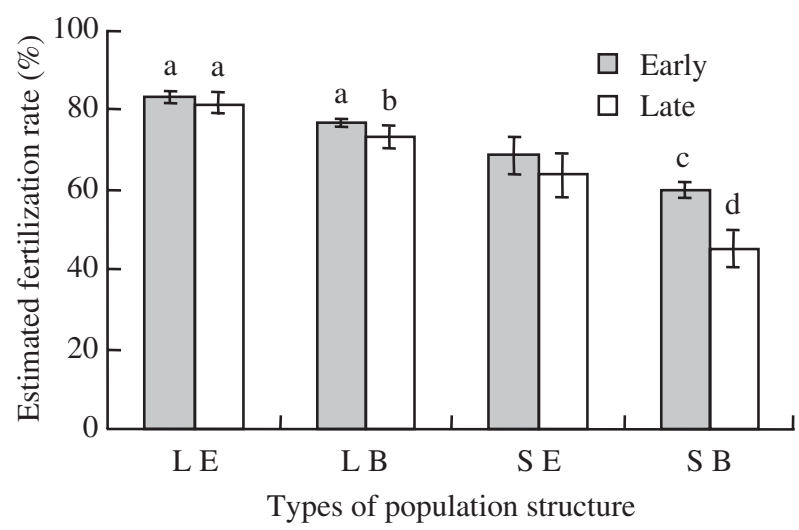

Fig. 7. Hapalogaster dentata. Temporal change in estimated fertilization rate for each population based on male size and sex ratio (SR). L: large males in population, S: small males in population, E: equal SR, B: biased SR. See 'Materials and methods' for details. Different letters above bars indicate signifficant differences. For each treatment $\mathrm{n}=4$. Error bars are SE

groups based on the development stages of their eggs (mean number of collected crabs: LE population, early, $\mathrm{n}=11.3 \pm 1.1$, late, $\mathrm{n}=15.5 \pm 2.1$; LB population, early, $\mathrm{n}=12.5 \pm 1.0$, late, $\mathrm{n}=17.0 \pm 1.5$; SE population, early, $\mathrm{n}=10.0 \pm 1.1$, late, $\mathrm{n}=13.0 \pm 0.7$; SB population, early, $\mathrm{n}=12.3 \pm 1.1$, late, $\mathrm{n}=14.3 \pm 1.3$ ). Females that carried no clutch occurred in all artificial populations except for the LE population: the LB and SE populations had 2 populations with 1 female that carried no clutch; the SB population had 2 populations with 2 females that carried no clutch, and 2 populations with 1 female that carried no clutch.

Three-way ANOVA (Table 1) showed that male size, sex ratio, and time of female mating were significant for the fertilization rate of females. A Bonferroni multiple-comparisons test (adjusted $\alpha=0.00625$ ) showed significant differences (Fig. 7). The fertilization rate of females was significantly higher in the populations consisting of large males, or in the populations with a

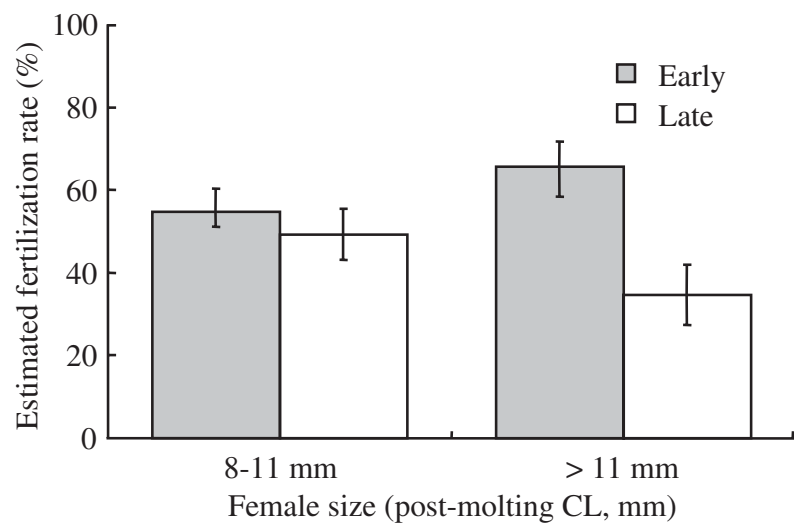

Fig. 8. Hapalogaster dentata. Temporal change in estimated fertilization rate of females of different body size in the SB population. For each treatment $\mathrm{n}=4$. Error bars are $\mathrm{SE}$

1:1 SR. The mean fertilization rate of females mated in the early reproductive season was significantly higher than for females mated in the late reproductive season. Two-way interactions between male size and sex ratio, and male size and time of female mating were nearly significant (Table 1).

Females collected from each SB population were divided into 4 groups based on CL and time of female mating (mean number of collected crabs: small female, early, $\mathrm{n}=6.0 \pm 0.4$, late, $\mathrm{n}=8.8 \pm 1.6$; large female, early, $\mathrm{n}=6.5 \pm 0.6$, late, $\mathrm{n}=4.4 \pm 0.5$ ). Two-way ANOVA detected a 2-way interaction between female size and time of female mating (female size $\times$ female mating timing: $F_{1,12}=4.84, \mathrm{p}=0.048$; Levene test, $\mathrm{p}=$ 0.74 , Fig. 8). Thus, the fertilization rate of large females was more variable with time of mating than for small females, and was lower when the time of female mating was late.

\section{DISCUSSION}

Both male mating frequency and male size caused sperm limitation in female Hapalogaster dentata in this study. In laboratory experiments, the number of ejaculated sperm and fertilization rate decreased with increasing male mating frequency, indicating that the decline in fertilization rate was caused by insufficient sperm supply. The degree of decrease in reproductive success of females was significantly different between the male size classes. Compared with females mated by large males, the decrease in reproductive success of females mated by small males was sharp, and the number of females that small males mated successfully was fewer, indicating male $H$. dantata have a sizedependent reproductive potential. The size-dependent reproductive potential in males resulted from the num- 
ber of sperm in the vasa deferentia of smaller males being smaller than for larger males. In other crabs, larger males had more abundant sperm than smaller males (Sapelkin \& Fedoseev 1986, Jivoff 1997, Sato et al. 2005b, 2006) and passed larger ejaculate to each mate than did small males (Jivoff 1997, Sato et al. 2006). Also in H. dentata, a decrease in ejaculate size with increasing mating frequency would differ between male size classes, which may result in differences in the degree of decrease in reproductive success of females with increasing male mating frequency between male size classes. Different decrease in the reproductive success of females with increasing male mating frequency between the male size classes was also observed in 2 commercially fished lithodid crabs, the spiny king crab Paralithodes brevipes (Sato et al. 2005b) and the red king crab P. camtschaticus (Paul \& Paul 1990).

Large male blue crab Callinectes sapidus recovers fully within approximately 9 to $20 \mathrm{~d}$ after mating, but small males do not increase the number of sperm for at least 3 d after mating (Kendall et al. 2001). In this study of Hapalogaster dentata, the recovery rate of sperm in the vasa deferentia differed with male size. However, the number of sperm did not recover completely even $20 \mathrm{~d}$ after male depletion, even with large males (at least for CL 13 to $14 \mathrm{~mm}$ ). The mating period is so short that production of new spermatophores may be too late before the mating period ends. The spiny king crab also has a low recovery rate of spermatophores (Sato et al. 2005b, 2006).

The effects of female delayed mating have been reported for large crustacean decapods. Female red king crab and other species are receptive and can successfully mate within a limited period after they molt (McMullen 1969, Paul \& Adams 1984, Sainte-Marie \& Lovrich 1994). Delayed mating can also result in females spawning nonfertilized eggs (Paul \& Adams 1984), or having a reduced fertilization rate (Sato et al. 2005a). In this study, delayed mating did not affect the fertilization rate of Hapalogaster dentata, but, like some large crabs, as the number of days after female molting increased, the number of females that failed to successfully spawn increased. The main cause of spawning failure was egg extrusion before adding a male to mate. These results indicate that female $H$. dentata have a limited period when they are sexually receptive.

Although Hapalogaster dentata differs in many aspects from commercially important lithodid crabs, their reproductive behavior and potential strongly resemble commercially important lithodid crabs, such as king crab (Goshima et al. 1995). In this study, $H$. dentata had some reproductive potential characteristics that are similar to those of commercially important lithodid crabs and that influence the probability that sperm is limiting and make females vulnerable to male absence during the reproductive season. Therefore, using $H$. dentata as a model species for commercially important lithodid crabs, such as the king crab, is valid for estimating the effects of population demography change by male-only fishing on the reproductive success of females.

In Kattoshi, the SR of the stone crab is 1:1 during the reproductive season (Goshima et al. 1995). The sizes of individuals participating in guarding pairs were 9.5 to $21.1 \mathrm{~mm}$ CL for males and 8.0 to $15.0 \mathrm{~mm} \mathrm{CL}$ for females, indicating these males mate with most females under natural conditions (Goshima et al. 2000). From the relationship between male CL and frequency of males guarding females, males larger than $11 \mathrm{~mm}$ CL mate most often, and males 13 to $15 \mathrm{~mm} \mathrm{CL}$ are most abundant among the other size classes of males guarding females (Goshima et al. 2000). Therefore, in this study, in the case of size of individual participating in mating, LE populations were most similar to the natural Hapalogaster dentata population, and SB populations were most similar to commercially maleonly fished lithodid crab populations.

Because a decrease in male crab density reduces the frequency of female encounters with males (Gray \& Powell 1964, Powell et al, 1974, Ennis 1980, Smith \& Jamieson 1991), females would tend to fail to mate within the limited sexually receptive period after molting in populations consisting of few small males. Smaller males may rapidly deplete their sperm reserve and thus the number of males available for mating would decrease progressively during the reproductive season. Thus, as male size in a population decreases, the probability that females fail to encounter potent males increases. These speculations are consistent with our results where the total number of females with no clutch in SB populations was more than that for LB populations, and was the largest among the 4 types of artificial populations: females with no clutch were in 2 SE populations, but did not occur in LE populations. The decrease in male size and skewed SR toward females decreased the reproductive success of females through female sexually receptive period after molting in Hapalogaster dentata. These results suggest that as the minimum legal size for males decreases, the crab density in fished populations should be kept as high as possible. This will avoid a decrease in female reproductive success, especially in species that have females with a limited period of receptivity and that have males with size-dependent reproductive potential such as the spiny king crab (Sato et al. 2005a,b) and the red king crab (McMullen 1969, Paul \& Paul 1990). Establishing marine protected areas (e.g. sanctuaries) (Allison et al. 1998) may be one way to partially and 
locally avoid having unmated females and to maintain recruitment to fished crab populations.

In this study, male size, SR, and time of female mating significantly influenced the fertilization rate of females. Two nearly significant 2-way interactions occurred between male size and SR, and male size and time of female mating. These results strongly suggest that (1) the fertilization rate of females was more variable with SR in populations consisting of small males than in populations consisting of large males, and was lower when the SR was skewed toward females (i.e. when the predicted frequency of male mating is high), and (2) the fertilization rate of females was more variable with time of female mating in populations consisting of small males than in populations consisting of large males, and was lower when the time of female mating was late. Smaller male Hapalogaster dentata were depleted more easily by successive matings than larger males and had a lower sperm recovery rate, resulting in the smallest mean fertilization rate among SB populations. Females that mated with smaller males, especially in the late reproductive season, would thus have a low fertilization rate. Females that mated with smaller males in SE and SB populations in the late reproductive season had a lower reproductive success than females in LE and LB populations that mated in the late reproductive season. However, a 3way interaction between male size, SR, and time of female mating was not detected, which may have resulted from experimental error. A decrease in male size and a skewed SR toward females decreased the fertilization rate of females through sperm limitation, and formed a gradient of the fertilization rate in response to their time of mating.

Large male-only fishing is used for many important commercially crabs, such as the red king crab (Powell et al. 1973), spiny king crab (Sato et al. 2005b) and snow crab Chionoecetes opilio (Ennis et al. 1990), in which a decrease in male size and skewed SR toward females occur (Paul \& Adams 1984, Ennis et al. 1988, 1990, Sato et al. 2005b). The minimum legal size of males would control the degree of change in population structure. This would influence the probability of sperm limitation in fished populations where males have a size-dependent reproductive potential and a low recovery rate of sperm as shown in Hapalogaster dentata, spiny king crab (Sato et al. 2005b, 2006) and red king crab (Paul \& Paul 1990). To avoid sperm limitation in such fished populations the reproductive potential of males in each size class and the number of females that participate in matings in fished populations should be examined to decide the minimum legal size for crabs to be caught.

The number of eggs spawned often correlates with female size (Sato \& Abe 1941, Haynes 1968, Prager et al. 1990, Annala 1991, Sainte-Marie 1993). As females increase in size, more sperm is necessary for successful fertilization. In species showing a decrease in male reproductive output with increase in mating frequency and a low recovery rate, the number of sperm available for females to fertilize their eggs decreases progressively throughout the reproductive season (Sato et al. 2005b). This trend is especially severe for larger females that need more sperm to fertilize their eggs than for small females in late reproductive season. Thus, in the SB population, larger females that mated in the late reproductive season had the smallest fertilization rate among the 4 treatments. Larger females must mate earlier in a reproductive season in a fished population. However, in some long-lived decapods it appears that smaller female crabs usually molt and mate earlier in a reproductive season than larger females in general (Lipcius 1985, Orensanz et al. 1995, Hankin et al. 1997). If so, the degree of decrease in fertilization rate may differ with female size. As a result, most larger females that spawn many eggs may fail to acquire sufficient sperm to fertilize their eggs, and the influence of male-only fishing on the reproductive success of stocks would be great in such species.

Results of this study using Hapalogaster dentata as a model species suggest that a decrease in male size and a skewed SR toward females (as seen in the male-only fished populations) may influence the reproductive success of females and the probability that females delay mating in commercially important lithodid crabs. Male-only fishing caused a temporal change in the reproductive success of females. The temporal change differs with female size, which may enable us to detect whether sperm is limiting in wild populations by investigating the reproductive success of females. The temporal change in reproductive success of females differing with female size, as seen in this study, may be a strong selection for female mating strategy with the time of mating depending on their body size and availability of sperm. A strong potential for evolution in response to the selective force of fishing mortality may exist in fished populations (e.g. Miller \& Kapuscinski 1994, Heino 1998, Law 2000), and human-manipulated populations may rapidly evolve (Hendry et al. 1998, Thompson 1998). In the future, the evolutionary effects of fishing should be included in fishery management decisions.

Acknowledgements. We thank the staff of Usujiri Marine Station, Aquatic Research Station, Field Science Center for Northern Biosphere, Hokkaido University who kindly helped us with the experiments. We also thank all members of the Laboratory of Marine Biodiversity, Graduate School of Fisheries Sciences, Hokkaido University, for their discussions. 


\section{LITERATURE CITED}

Abbe GR, Stagg C (1996) Trends in blue crab (Callinectes sapidus Rathbun) catches near Calvert Cliffs, Maryland, from 1968 to 1995 and their relationship to the Maryland commercial fishery. J Shellfish Res 15:751-758

Allison GW, Lubchenco J, Carr MH (1998) Marine reserves are necessary but not sufficient for marine conservation. Ecol Appl, Suppl 8:S79-S92

Annala JH (1991) Factors influencing fecundity and population egg production of Jasus species. In: Wenner A, Kuris A (eds) Crustacean egg production. Balkema, Rotterdam, p 301-315

Birkhead TR (1991) Sperm depletion in the Bengalese finch, Lonchura atriata. Behav Ecol 2:267-275

Bissoondath CJ, Wiklund C (1996) Effects of male mating history and body size on ejaculate size and quality in two polyandrous butterflies, Pieris napi and Pieris rapae (Lepidoptera: Pieridae). Funct Ecol 10:457-464

Cole RG, Ayling TM, Creese RG (1990) Effects of marine reserve protection at Goat Island, northern New Zealand. NZ J Mar Freshw Res 24:197-210

Cunningham CW, Blackstone NW, Buss LW (1992) Evolution of king crabs from hermit crab ancestors. Nature 355: 539-542

Dewsbury DA (1982) Ejaculate cost and male choice. Am Nat 119:601-610

Ennis GP (1980) Size-maturity relationships and related observations in Newfoundland populations of the lobster (Homarus americanus). Can J Fish Aquat Sci 37:945-956

Ennis GP, Hooper RG, Taylor DM (1988) Functional maturity in small male snow crabs (Chionoecetes opilio). Can J Fish Aquat Sci 45:2106-2109

Ennis GP, Hooper RG, Taylor DM (1990) Changes in the composition of snow crab (Chionoecetes opilio) participating in the annual breeding migration in Bonne Bay, Newfoundland. Can J Fish Aquat Sci 47:2242-2249

Gage MJG, Cook PA (1994) Sperm size or numbers? Effects of nutritional stress on eupyrene and apyrene sperm production strategies in the moth Plodia interpunctella (Lepidoptera: Pyralidiae). Funct Ecol 8:594-599

Goshima S, Ito K, Wada S, Shimizu M, Nakao S (1995) Reproductive biology of the stone crab Hapalogaster dentata (Anomura: Lithodidae). Crust Res 24:8-18

Goshima S, Kanazawa M, Yoshino K, Wada S (2000) Maturity in male crab Hapalogaster dentata (Anomura: Lithodidae) and its application for fishery management. J Crust Biol 20:641-646

Gray GW, Powell GC (1964) Sex ratios and distribution of spawning king crabs in Alitak Bay, Kodiak Is., Alaska (Decapoda, Anomura, Lithodidae). Crustaceana 10:303-309

Hankin DG, Butler TH, Wild PW, Xue QL (1997) Does intense fishing on males impair mating success of female Dungeness crab? Can J Fish Aquat Sci 54:655-669

Haynes EB (1968) Relation of fecundity and egg length to carapace length in the king crab, Paralithodes camtschatica. Proc Natl Shellfish Assoc 58:60-62

Heino M (1998) Management of evolving fish stocks. Can J Fish Aquat Sci 55:1971-1982

Hendry AP, Hensleigh JE, Reisenbichler RR (1998) Incubation temperature, developmental biology, and the divergence of sockeye salmon (Oncorhynchus nerka) within lake Washington. Can J Fish Aquat Sci 55:1387-1394

Hines AH, Jivoff PR, Bushman PJ, van Montfrans J, Reed SA, Wolcott DL, Wolcott TG (2003) Evidence for sperm limitation in the blue crab, Callinectes sapidus. Bull Mar Sci 72: $287-310$
Jivoff PR (1997) Sexual competition among male blue crab, Callinectes sapidus. Biol Bull 193:368-380

Kendall MS, Wolcott DL, Wolcott TG, Hines AH (2001) Reproductive potential of individual male blue crabs, Callinectes sapidus, in a fished population: depletion and recovery of sperm number and seminal fluid. Can J Fish Aquat Sci 58:1168-1177

Kwei EA (1978) Size composition, growth and sexual maturity of Callinectes latimanus (Rathbun) in two Ghanaian lagoons. Zool J Linn Soc 64:151-175

Law R (2000) Fishing, selection, and phenotypic evolution. ICES J Mar Sci 57:659-668

Lipcius RN (1985) Size-dependent reproduction and molting in spiny lobsters and other long-lived decapods. In: Crustacean Issues. Vol. 3. Factors in adult growth. Balkema Press, Rotterdam, p 129-148

MacDiarmid AB, Butler MJ (1999) Sperm economy and limitation in spiny lobsters. Behav Ecol Sociobiol 46:14-24

McMullen JC (1969) Effects of delayed mating on the reproduction of king crab (Paralithodes camtschatica). J Fish Res Bd Canada 26:2737-2740

Miller L, Kapuscinski A (1994) Estimation of selection differentials from fish scales: a step towards evaluation of genetic alteration of fish size in exploited populations. Can J Fish Aquat Sci 51:774-783

Nakatsuru K, Kramer DL (1982) Is sperm cheap? Limited male fertility and female choice in the lemon tetra (Pisces, Characidae). Science 216:753-755

Orensanz JM, Parma AM, Armstrong DA, Armstrong J, Wardrup P (1995) The breeding ecology of Cancer gracilis (Crustacea: Decapoda: Cancridae) and the mating systems of cancrid crabs. J Zool 235:411-437

Paul A J, Adams AE (1984) Breeding and fertile period for female Chionoecetes bairdi (Decapoda, Majidae). J Crust Biol 4:589-594

Paul JM, Paul AJ (1990) Reproductive success of sublegal size male red king crab (Paralithodes camtschatica) with access to multiple mates. Proc Int Symp King \& Tanner Crabs Nov. 1989, Anchorage, Alaska:37-50

Pitnick S (1996) Investment in testes and the cost of making long sperm in Drosophila. Am Nat 148:57-80

Pitnick S, Markow TA (1994) Male gametic strategies: sperm size, testes size, and the allocation of ejaculate among successive mates by sperm-limited fly Drosophila pachea and its relatives. Am Nat 143:785-819

Powell GC, James KE, Hurd CL (1974) Ability of male king crab, Paralithodes camtschatica, to mate repeatedly, Kodiak, Alaska, 1973. Fish Bull US 72:171-179

Powell GC, Shafford B, Jones M (1973) Reproductive biology of young adult king crabs Paralithodes camtschatica (Tilesius) at Kodiak, Alaska. Proc Natl Shellfish Assoc 63:77-87

Prager MH, McConaugha JR, Jones CM, Geer PJ (1990) Fecundity of blue crab, Callinectes sapidus, in Chesapeake Bay: Biological, statistical and management considerations. Bull Mar Sci 46:170-179

Preston BT, Stevenson IR, Pemberton JM, Wilson K (2001) Dominant rams lose out by sperm depletion. Nature 409: 681-682

Rondeau A, Sainte-Marie B (2001) Variable mate-guarding time and sperm allocation by male snow crab (Chionoecetes opilio) in response to sexual competition, and their impact on the mating success of females. Biol Bull 201: $204-217$

Royer L, McNeil JM (1993) Male investment in the European corn borer, Ostrinia nubilalis (Lepidoptera Pyralidae)impact on female longevity and reproductive performance. Funct Ecol 7:209-215 
Rutowski RL, Gilcrist GW, Terkanian B (1987) Female butterflies mated with recently mated males show reduced reproductive output. Behav Ecol Sociobiol 20:319-322

Sainte-Marie B (1993) Reproductive cycle and fecundity of primiparous and multiparous female snow crab, Chionoecetes opilio, in the northwest Gulf of Saint Lawrence. Can J Fish Aquat Sci 50:2147-2156

Sainte-Marie B, Lovrich GA (1994) Delivery and storage of sperm at first mating of female Chionoecetes opilio (Brachyura: Majidae) in relation to size and morphometric maturity of male parent. J Crust Biol 14:508-521

Sainte-Marie B, Sévigny JM, Carpentier M (2002) Interannual variability of sperm reserves and fecundity of primiparous females of the snow crab (Chionoecetes opilio) in relation to sex ratio. Can J Fish Aquat Sci 59:1932-1940

Sapelkin AA, Fedoseev VY (1986) Spermatophore formation and accumulation of sexual products in male king crab. Biol Morya 12:34-38

Sato S, Abe Y (1941) Fecundity of the king crab, Paralithodes brevipes. Sci Rep Hokkaido Fish Exp Sta 481:244-246 (in Japanese)

Sato T, Ashidate M, Goshima S (2004) A new method to extract sperm from spermatophores of the male spiny king

Editorial responsibility: Otto Kinne (Editor-in-Chief), Oldendorf/Luhe, Germany crab Paralithodes brevipes (Anomura: Lithodidae). Crust Res 33:1-14

Sato T, Ashidate M, Goshima S (2005a) Negative effects of delayed mating on the reproductive success of female spiny king crab, Paralithodes brevipes. J Crust Biol 25: 105-109

Sato T, Ashidate M, Jinbo T, Goshima S (2006) Variation of sperm allocation with male size and recovery rate of sperm numbers in spiny king crab Paralithodes brevipes. Mar Ecol Prog Ser (in press)

Sato T, Ashidate M, Wada S, Goshima S (2005b) Effects of male mating frequency and male size on ejaculate size and reproductive success of female spiny king crab, Paralithodes brevipes. Mar Ecol Prog Ser 296:251-262

Smith BD, Jamieson GL (1991) Possible consequences of intensive fishing for males on the mating opportunities of Dungeness crabs. Trans Am Fish Soc 120:650-653

Svensson MGE, Marling E, Löfqvist J (1998) Mating behavior and reproductive potential in the turnip moth Agrotis segetum (Lepidoptera: Noctuidae). J Insect Behav 11: 343-359

Thompson JN (1998) Rapid evolution as an ecological process. Trends Ecol Evol 13:329-332

Submitted: December 29, 2004; Accepted: January 10, 2006

Proofs received from author(s): April 4, 2006 